\title{
CARACTERÍSTICAS FISIOLÓGICAS DE MICROTOMATEIROS FITOCROMO-MUTANTES
}

\author{
Physiological characteristics of micro-tomato (Lycopersicon esculentum P. Miller) \\ phytochrome-mutants
}

\author{
Hyrandir Cabral de Melo', Evaristo Mauro de Castro ${ }^{2}$, Ângela Maria Soares', \\ Cynthia de Oliveira ${ }^{4}$, Sílvio Júnio Ramos ${ }^{5}$
}

\begin{abstract}
RESUMO
Objetivou-se, neste trabalho, caracterizar aspectos fisiológicos de microtomateiros (Lycopersicon esculentum P. Miller cv. Micro-Tom) fitocromo-mutantes. A cultivar Micro-Tom e os mutantes aurea (deficiente na biossíntese do cromóforo dos fitocromos), atroviolacea (atv) e high pigment 1 ( $h p l$; ambos superexpressam eventos mediados por fitocromos) foram cultivados em condições controladas de luz e temperatura e caracterizados no estágio de floração. O mutante $h p l$ obteve as maiores taxas de fotossíntese potencial e de conteúdo de carotenóides. O mutante aurea manteve taxas de fotossíntese potencial similares à cultivar Micro-Tom, mesmo expressando o mais baixo conteúdo de clorofilas, e também expressou o maior conteúdo de nitrogênio entre os demais microtomateiros. Os mutantes aurea e $h p l$ obtiveram os menores conteúdos de açúcares solúveis totais. O mutante atv expressou o maior conteúdo de clorofilas e também a menor razão clorofila $a / b$.
\end{abstract}

Termos para indexação: Lycopersicon esculentum, Micro-Tom, pigmentos fotossintéticos, fotossíntese.

\section{ABSTRACT}

The objective of this work was to characterize physiological aspects of micro-tomato (Lycopersicon esculentum P. Miller cv. Micro-Tom) phytochrome-mutants. Plants of Micro-Tom cultivar and aurea (deficient in phytochrome chromophore biosynthesis), high pigment $1(\mathrm{hpl})$ and atroviolacea (atv) (both super express phytochrome events-mediated) mutants were cultivated under controlled light and temperature and evaluated in flowering stage. The $h p 1$ mutant expressed the highest rates of potential photosynthesis and also the content of total carotenoids. Aurea mutant maintained similar potential photosynthesis rates as the Micro-Tom cultivar, even containing low chlorophyll content, and expressed the highest content of nitrogen among all micro-tomatoes studied. Total soluble sugars were lower in aurea and $\mathrm{hpl}$ mutants. The atv mutant expressed the highest content of chlorophylls and also the lowest rate of chlorophyll $\mathrm{a} / \mathrm{b}$.

Index terms: Lycopersicon esculentum, Micro-Tom, photosynthetic pigment, photosynthesis.

(Recebido em 15 de outubro de 2007 e aprovado em 24 de junho de 2008)

\section{INTRODUÇÃO}

$\mathrm{O}$ uso de tomateiro (Lycopersicon esculentum $\mathrm{P}$. Miller) como modelo para estudos fisiológicos possui vantagens em relação ao uso de Arabidopsis thaliana (L.) Heynh., a exemplo da diversidade de metabólitos secundários, tecidos que facilitam análises bioquímicas, além do padrão morfogenético (PRATT et al., 1997). No entanto, o elevado porte das plantas e o longo ciclo de vida surgem como desvantagens em relação ao uso de $A$. thaliana. A cultivar em miniatura, Micro-Tom
(Lycopersicon esculentum cv Micro-Tom) foi proposta por Meissner et al. (1997) como um modelo genético, que produz frutos e sementes viáveis, e podem ser cultivadas em vasos de 50-150 mL de substrato, completando seu ciclo de vida entre 70-90 dias, superando assim as desvantagens do cultivo de tomateiro em relação a A. thaliana, para fins de pesquisa. Atualmente Micro-Tom (MT) tem sido proposta como a cultivar preferencial para pesquisas a nível molecular em tomateiro (MARTÍ et al., 2006).

Plantas fitocromo-mutantes possibilitam o estudo dos espectros vermelho e vermelho distante da radiação

\footnotetext{
'Licenciado em Ciências Agrícolas, Doutor em Fisiologia Vegetal - Instituto Universitário do Norte Mato-Grossense/IUNMAT - Universidade Federal do Mato Grosso/UFMT - Campus Universitário - Avenida Fernando Corrêa, s/n - 78060-900 - Cuiabá, MT - hyrandir@yahoo.com.br ${ }^{2}$ Engenheiro Florestal, Doutor, Professor Adjunto - Departamento de Biologia/DBI - Universidade Federal de Lavras/UFLA - Cx. P. 3037 - $37200-000$ Lavras, MG - emcastro@ufla.br

${ }^{3}$ Física, Doutora, Professora Adjunto - Departamento de Biologia/DBI - Universidade Federal de Lavras/UFLA - Cx. P. 3037 - $37200-000$ - Lavras, MG amsoares@ufla.br

${ }^{4}$ Agrônoma, Mestranda em Fisiologia Vegetal - Departamento de Biologia/DBI - Universidade Federal de Lavras/UFLA - Cx. P. 3037 - $37200-000$ Lavras, MG - cynthia_ufla@yahoo.com.br

${ }^{5}$ Engenheiro Agrônomo, Doutorando em Ciência do Solo - Departamento de Ciência do Solo/DCS - Universidade Federal de Lavras/UFLA - Cx. P. 3037 37200-000 - Lavras, MG - silviojramos@gmail.com.br
} 
sobre eventos da fotomorfogênese, o qual tem sido dificultado pela complexidade de interação entre os diferentes fotorreceptores (CHEN et al., 2004; SCHITTENHELM et al., 2004). O mutante mais estudado é o aurea, deficiente em fitocromo A (phyA) assim como na síntese do cromóforo, o que o torna deficiente em todas as espécies de fitocromo (SHARMA et al., 1993). O mutante high pigmentl ( $h p l)$ e atroviolacea (atv) apresentam mutação na via de transdução de sinais, expressando hipersensibilidade de respostas em processos mediados por fitocromo (PETERS et al., 1998).

Mutantes aurea têm níveis de clorofila e antocianina reduzidos durante todo o ciclo de vida das plantas, mas principalmente em estágio inicial de crescimento (TERRY $\&$ KENDRICK, 1999), enquanto que nos mutantes $h p l$ e atv o conteúdo desses pigmentos, além dos carotenóides, são mais elevados em relação às plantas selvagens (KERCKHOFFS et al., 1997).

Aspectos morfológicos e genéticos têm sido estudados em microtomateiros (MARTÍ et al., 2006; MEISSNER et al., 1997) e naqueles fitocromo-mutantes, o potencial de regeneração in vitro (CARVALHO, 2003). Diversos aspectos fisiológicos ainda não foram caracterizados, inclusive em mutantes de porte normal, os quais são fundamentais para o entendimento dos complexos efeitos da radiação sobre processos do desenvolvimento dependentes de fitocromo.

Objetivou-se, neste trabalho caracterizar fisiologicamente microtomateiros, cultivar MT, fitocromomutantes.

\section{MATERIAL E MÉTODOS}

As sementes dos microtomateiros, utilizados neste trabalho, foram gentilmente cedidas pela equipe de pesquisa do prof. Lazaro Ramos e Rogério F. Carvalho (ESALQ-USP). A semeadura dos microtomateiros cultivar Micro-Tom e seus mutantes aurea, hpl e atroviolacea, foi realizada em bandejas de isopor, utilizando-se substrato Plantmax ${ }^{\circledR}$ e vermiculita, na proporção de $1: 1$, para enchimento das células. As bandejas foram acondicionadas em câmaras de crescimento com temperatura média de $27^{\circ} \mathrm{C}$ e radiação média de 150 ìmol m $\mathrm{m}^{-2} \mathrm{~s}^{-1}$ a partir de lâmpadas fluorescentes brancas, e fotoperíodo de 16 horas. As bandejas foram regadas duas vezes ao dia, mantendo a umidade do substrato próximo à capacidade de campo.

Quinze dias após a semeadura, foram escolhidas 30 mudas de cada mutante e da cultivar MT, de acordo a similaridade em porte e vigor, e transplantadas para vasos plásticos com capacidade de $150 \mathrm{~mL}$. O substrato do vaso foi composto de Plantmax ${ }^{\circledR}$ e vermiculita $(1: 1)$ e $0,5 \mathrm{~g}$ de
NPK, na formulação 4-14-8, distribuído na borda de cada vaso. As plantas foram acondicionadas em câmaras de crescimento iluminadas com lâmpadas fluorescentes brancas, recebendo uma radiação média de $150 \mathrm{ìmol} \mathrm{m} \mathrm{m}^{-2} \mathrm{~s}^{-}$ ${ }^{1}$, na altura central da copas das plantas adultas, com fotoperíodo de 16 horas, durante o período diurno (no qual a temperatura era mais elevada). A irrigação foi realizada diariamente, duas vezes ao dia, mantendo a umidade do substrato próximo à capacidade de campo. No interior das câmaras de crescimento, a temperatura máxima diária foi de $32^{\circ} \mathrm{C}$ e mínima noturna de $18^{\circ} \mathrm{C}$, medida na altura central da copa das plantas adultas, sendo a temperatura média de $26^{\circ} \mathrm{C}$

Após o transplantio das mudas, uma vez por semana, era realizada adubação foliar das plantas, utilizando-se um borrifador manual com uma solução diluída 10 vezes a partir da solução estoque, que era composta de $7 \mathrm{~g}$ do composto nutricional de Peters ${ }^{\circledR} 20-20-20+20 \mathrm{~g}$ de $\mathrm{Ca}\left(\mathrm{NO}_{3}\right)_{2}+5 \mathrm{~g}$ de $\mathrm{MgSO}_{4}+3 \mathrm{~g} \mathrm{~K}_{2} \mathrm{SO}_{4}+$ água até completar 1L.

No $30^{\circ}$ dia após o transplantio das mudas foram realizadas avaliações de resistência estomática (re) e transpiração $(E)$ no folíolo da região mediana da terceira folha completamente expandida, do ápice para a base da planta. Quatro horas após o início do período de luz foram realizadas três avaliações, de quatro em quatro horas, com o auxílio de um Porômetro (LICOR LI-1600), em cinco plantas de cada microtomateiro estudado e posteriormente os dados foram agrupados para obtenção das médias.

Um dia após as avaliações de re e $E$ foram realizadas as avaliações de fotossíntese potencial $\left(A_{\text {pot }}\right)$, através do método de evolução de oxigênio (DELIEU \& WALKER, 1983). A determinação foi realizada à temperatura de $30^{\circ} \mathrm{C}$, em três plantas de cada microtomateiro estudado, nos mesmos folíolos utilizados para determinação da re e $E$. Nesse processo foi utilizada fonte de luz fornecendo 1200 ìmol $\mathrm{m}^{-2} \mathrm{~s}^{-1}$ de densidade de fluxo de fótons fotossinteticamente ativos.

No $32^{\circ}$ dia após o transplantio das mudas, folíolos localizados na mesma posição onde foram realizadas as avaliações das trocas gasosas foram coletados e discos foliares retirados da região mediana do limbo foliar, excetuando-se a nervura central e bordas do limbo foliar, para análises de clorofilas e carotenóides. Para as análises de proteínas, açucares solúveis totais (AST) e nitrogênio total (N) utilizou-se material seco. Folíolos para determinação de todas as análises bioquímicas foram coletados quatro horas após o início do período de luz e as avaliações foram realizadas em três plantas para cada microtomateiro estudado. 
A metodologia de Kjeldahl (1883) foi utilizada para determinação do teor de nitrogênio total foliar. Para o teor de proteínas totais, utilizaram-se os valores obtidos para nitrogênio multiplicando-se pelo fator de conversão 6,25 (AOAC, 1970). Para análises de AST foi utilizado o método da antrona (DISCHE, 1962). O conteúdo de clorofilas foi determinado pelo método de Arnon (1949) e o de carotenóides totais pelo método de Higby (1962).

$\mathrm{O}$ experimento foi conduzido em delineamento inteiramente casualizado. Após análise de variância dos dados obtidos, utilizou-se o teste de Tukey, a 5\% de probabilidade, para agrupamento das médias em classes distintas.

\section{RESULTADOS E DISCUSSÃO}

O mutante aurea obteve valores de $A_{\text {pot }}$ similares à cultivar MT (Figura 1), mesmo expressando conteúdo de clorofilas a e b menor que todos os demais microtomateiros estudados (Figura 2). Observou-se, nesse mutante, o maior conteúdo de proteínas totais e nitrogênio total (Figura 3) e o menor conteúdo de carotenóides totais (Figura 4), relativos aos demais microtomateiros.

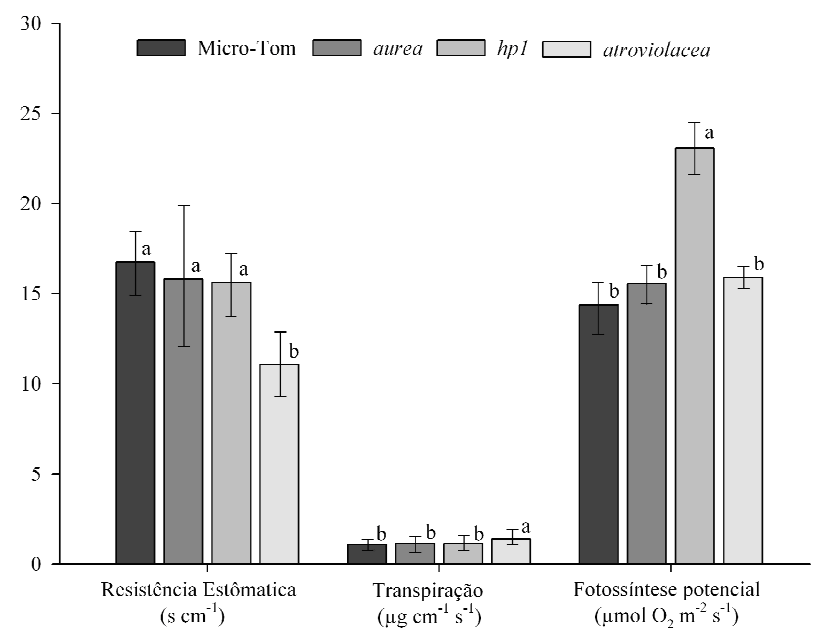

Figura 1 - Trocas gasosas em microtomateiros cultivar Micro-Tom e fitocromo-mutantes. Barras com mesma letra, dentro de um mesmo parâmetro de avaliação, não diferem entre si pelo teste de Tukey, a 5\% de probabilidade. LavrasMG, 2007.

O mutante atroviolacea obteve o maior conteúdo de clorofilas $a$ e $b$ e a menor razão clorofila $a / b$ (Figura 2), embora o conteúdo de nitrogênio total e proteínas totais tenham sido menores que todos os demais microtomateiros (Figura 3) e o conteúdo dos carotenóides tenha sido similar à cultivar MT (Figura 4).

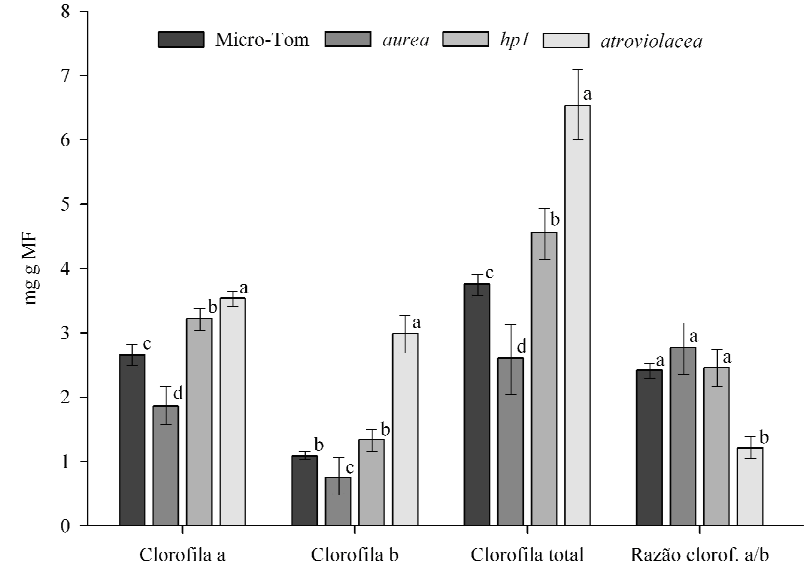

Figura 2 - Teor de clorofilas a, b, total e razão clorofila a/b em microtomateiros cultivar Micro-Tom e fitocromomutantes. Barras com mesma letra, dentro de um mesmo parâmetro de avaliação, não diferem entre si pelo teste de Tukey, a 5\% de probabilidade. Lavras-MG, 2007.

O mutante $h p l$ obteve as maiores taxas de $A_{\text {pot }}$ (Figura 1), em relação aos demais microtomateiros Os conteúdos de clorofila $a$ e total (Figura 2), nitrogênio total e proteínas totais foram superiores à cultivar MT e o teor de AST inferior à cultivar MT (Figura 3). Esse mutante expressou o maior conteúdo de carotenóides totais em relação aos demais microtomateiros (Figura 4).

A manutenção de altas taxas de fotossíntese potencial pelo mutante aurea, mesmo expressando o menor conteúdo de clorofilas, se comparado aos demais microtomateiros estudados, provavelmente esteja associada aos mais altos conteúdos de nitrogênio total e proteínas totais, observados para esse mutante, uma vez que a Rubisco (Ribulose 1,5-Bifosfato CarboxilaseOxigenase), enzima-chave no aparato fotossintético de plantas C3, representa aproximadamente $20 \%$ do total de nitrogênio foliar, em plantas de sol com boa disponibilidade de nutrientes (EVANS \& SEEMANN, 1984). Assim como neste trabalho, Becker et al. (1992), Koorneef et al. (1985) e López-Juez et al. (1990) também relatam a alta capacidade fotossintética do mutante aurea em relação à suas respectivas plantas selvagens, ainda que apresentem reduzido conteúdo de clorofila em relação a essas.

O maior conteúdo de proteínas totais do mutante $h p 1$, em relação à cultivar MT e ao mutante $a t v$, provavelmente tenha contribuído para a mais alta taxa de $A_{\text {pot }}$ observado para esse mutante, uma vez que essa mutação regula positivamente a expressão de proteínas de ligação à clorofila (CAB) e a Rubisco (PETERS et al., 1998). 
O maior conteúdo de clorofilas e a menor razão de clorofila $a / b$, observados no mutante atv são eventos de ocorrência comum em plantas de sombra (LIMA JUNIOR et al., 2006; NAKAZONO et al., 2001; DIGNART et al., 2009; DOUSSEAU et al., 2008). Provavelmente, a maior concentração de clorofilas tenha ocorrido devido ao maior número de cloroplastos por células do parênquima paliçádico (DIGNART et al., 2009). A menor razão clorofila $a / b$ tem sido relatada ocorrendo em resposta ao espectro vermelho distante da radiação, provocando um aumento quantitativo do fotossistema II, o qual é mais rico em clorofila $b$ que $a$ (CRITCHLEY, 1999). Essa maior concentração de clorofila b, provavelmente atue como um sistema de aclimatização das plantas ao ambiente no sentido de maximizar a absorção da radiação incidente (CHOW et al., 1990).

A redução do conteúdo de clorofilas observado no mutante aurea neste trabalho, comparado à cultivar MT, evidencia a importância dos fitocromos na síntese desse pigmento, uma vez que esste mutante tem redução no conteúdo de todos os tipos de fitocromos, no entanto, segundo Schittenhelm et al. (2004) o phyB é o tipo de fitocromo que mais influencia na síntese de clorofilas em plantas.

A capacidade fotossintética em plantas, geralmente, é proporcional ao conteúdo de nitrogênio (CRUZ et al., 2007), em função da sua alocação em proteínas-chaves no processo fotossintético (EVANS \& SEEMAN, 1984). No entanto, apesar do maior conteúdo de clorofilas observado, neste trabalho, para o mutante atv esse mutante expressou o menor conteúdo de nitrogênio e proteínas, embora esse menor conteúdo protéico não tenha afetado as taxas de $A_{\text {pot }}$ ao se comparar esse mutante à cultivar MT. Diferentemente do observado para o mutante atv, o maior conteúdo de nitrogênio total e o menor conteúdo de clorofila observados no mutante áurea, sugere a alocação da maior parte desse nitrogênio em proteínas, as quais foram encontradas as maiores concentrações nesse mutante. Mudanças na alocação de nitrogênio em função da mutação em fitocromos foram também observadas por Schittenhelm et al. (2004), onde, tomateiros mutantes que superexpressam phyB, Dara5, tiveram similar capacidade na assimilação de nitrogênio que plantas selvagens, no entanto um particionamento bastante diferenciado entre os órgãos das plantas.

Embora comumente haja uma correlação positiva entre taxas fotossintéticas e teor de açúcares solúveis em função da maior produção de fotoassimilados (CARVALHO et al., 2006) o mutante $h p l$, que apresentou as maiores taxas de $A_{\text {pot }}$, obteve o conteúdo de AST menor que a cultivar MT. Observou-se também que a concentração de AST no mutante aurea foi inferior à cultivar MT, apesar de serem similares quanto à $A_{\text {pot }}$ o que sugere além do
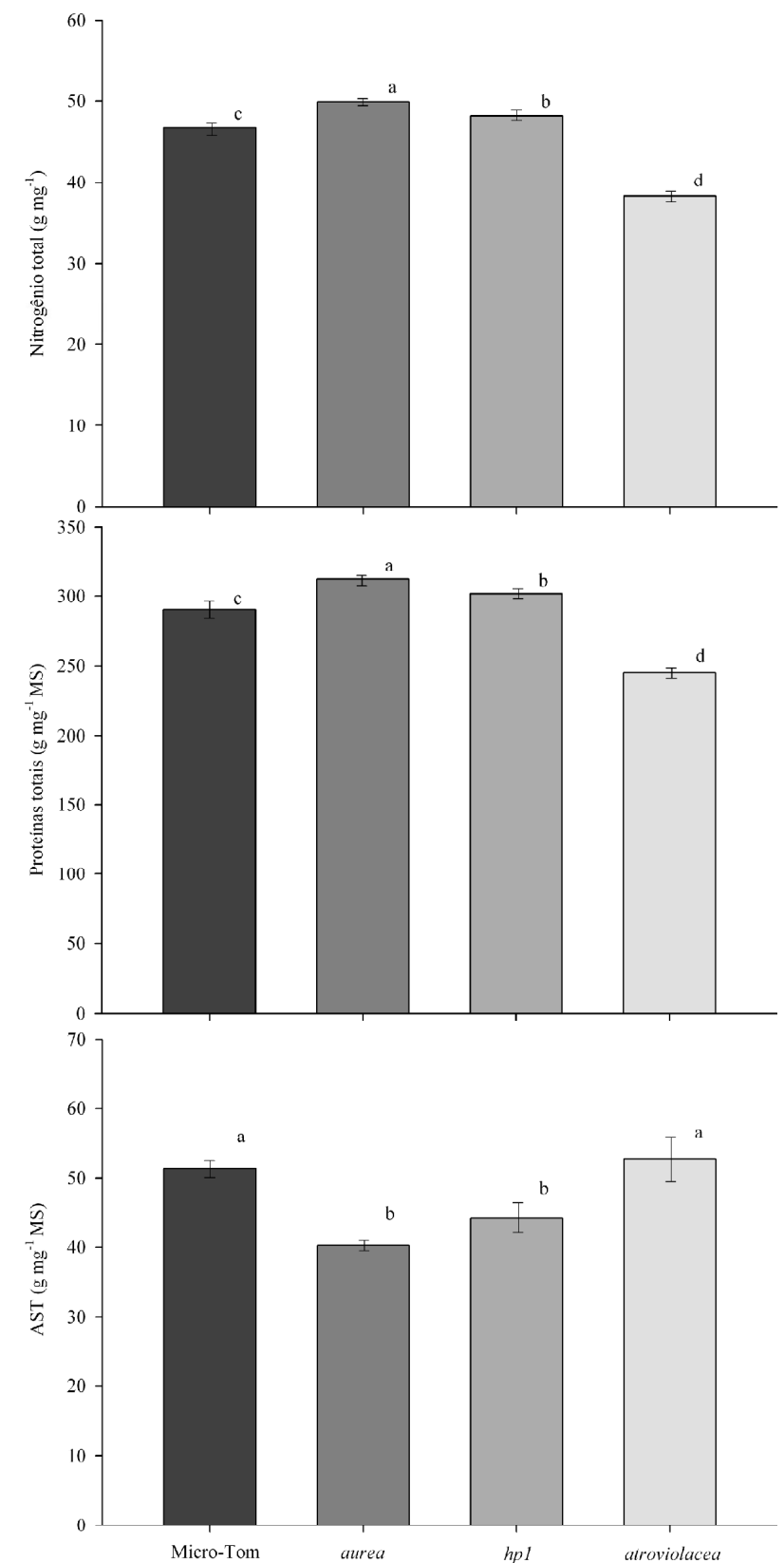

Figura 3 - Concentração de nitrogênio total, proteínas totais e açúcares solúveis totais (AST) em microtomateiros cultivar Micro-Tom e fitocromo-mutantes. Barras com mesma letra não diferem entre si pelo teste de Tukey, a 5\% de probabilidade. Lavras-MG, 2007.

potencial fotossintético as mutações associadas ao fitocromo provavelmente influenciaram a partição dos açucares solúveis para rotas de biossíntese de aminoácidos e proteínas nos mutantes aurea e atv. 


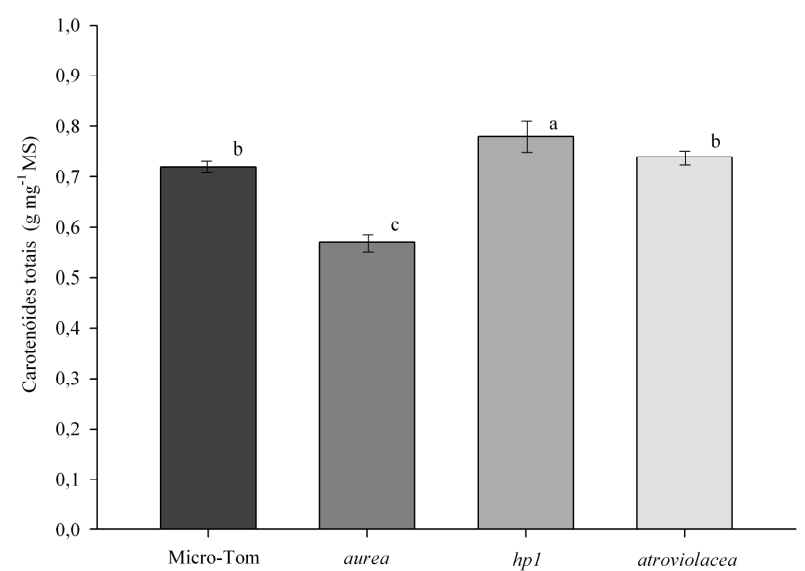

Figura 4 - Teor de carotenóides totais em folhas de microtomateiros cultivar Micro-Tom e fitocromo-mutantes. Barras com mesma letra não diferem entre si pelo teste de Tukey, a 5\% de probabilidade. Lavras-MG, 2007.

Para o tomateiro Dara-5, mutante que superexpressa phyB, Schittenhelm et al. (2004) observaram que os mutantes cultivados em casa de vegetação tinham menor conteúdo de AST, quando comparados às plantas selvagens, assim como observado neste trabalho para o mutante $h p l$. Yen et al. (1997) observaram maior concentração de carboidratos em tomateiros mutantes $h p l$ em relação às plantas selvagens e atribuíram essa maior concentração ao maior conteúdo de clorofilas desse mutante. Essa relação carboidratos/clorofila também pode ser observada neste trabalho, onde maior concentração de AST foi observada no mutante atv, o qual expressou o maior conteúdo de clorofilas dentre os demais microtomateiros, no entanto não foram observadas diferenças no conteúdo de AST entre os microtomateiros atv e MT.

Correlação positiva entre conteúdo de clorofila e carotenóides é geralmente encontrada em plantas, e é atribuída aos carotenóides uma função de fotoproteção às clorofilas (BARTLEY \& SCOLNIK, 1995). No entanto, apesar do mutante atv ter sido o microtomateiro que expressou o maior conteúdo de clorofilas, não obteve o maior conteúdo de carotenóides, indicando uma correlação não positiva entre o conteúdo desses dois pigmentos para esse mutante, enquanto que essa correlação foi positiva para o mutante aurea, o qual expressou o menor conteúdo de ambos os pigmentos. É possível que a baixa intensidade de radiação das condições do experimento tenha influenciado o baixo conteúdo de carotenóides relativo ao de clorofila no mutante atv, no sentido do não requerimento de um forte aparato contra danos fotooxidativos pelas plantas. O maior conteúdo de carotenóides totais observado no mutante $h p l$, em relação aos demais microtomateiros estudados, é um comportamento similar àquele encontrado em frutos de tomateiro desse mesmo mutante, quando comparados aos das plantas selvagens (LIU et al., 2004).

Embora atv e hpl sejam mutantes considerados super-responsivos a eventos desencadeados por fitocromos, diferenças encontradas entre esses mutantes neste trabalho, sugerem uma maior sensibilidade do mutante $h p l$ em responder positivamente à baixa intensidade de radiação, assim como observado em outros estudos para a síntese de antocianina (HUUB et al., 1997; KERCKHOFFS et al., 1997).

\section{CONCLUSÕES}

As trocas gasosas, conteúdos de clorofila, nitrogênio total, proteínas totais, açúcares solúveis totais e carotenóides em microtomateiros foram influenciados por mutações em fitocromo.

\section{AGRADECIMENTOS}

Aos professores Lazaro Ramos e Rogério F. Carvalho (ESALQ), pela doação das sementes.

\section{REFERÊNCIAS BIBLIOGRÁFICAS}

ARNON, D. I. Copper enzymes in isolated chloroplasts: polyphenoloxidase in Beta vulgaris. Plant Physiology, Wageningen, v. 24, p. 1-15, 1949.

\section{ASSOCIATION OF OFFICIAL AND AGRICULTURAL} CHEMISTRY. Official methods of analysis of the AOAC. 11. ed. Washinghton, DC, 1970. 108 p.

BARTLEY, G. E.; SCOLNIK, P. A. Plant carotenoids: pigments for photoprotection, visual attraction, and human health. The Plant Cell, v. 7, p. 1027-1038, 1995.

BECKER, T. W.; FOYER, C.; CABOCHE, M. Lightregulated expression of nitrate-reductase and nitratereductase genes in tomato and the phytocrome-deficient aurea mutant of tomato. Planta, Berlin, v. 188, p. 39-47, 1992.

CARVALHO, L. M.; CASALI, V. W. D.; LISBOA, S. P. Growth and metabolism of feverfew plants in response to the irradiance level. Horticultura Brasileira, Brasília, v. 24, p. 289-294, 2006. 
CARVALHO, R. F. Uso de mutantes fotomorfogenéticos no estudo da competência para regeneração in vitro em micro-tomateiro (Lycopersicon esculentum cv. MicroTom). 2003. 69 p. Dissertação (Mestrado) - Escola Superior de Agricultura Luiz de Queiroz, Piracicaba, 2003.

CHEN, M.; CHORY, J.; FANKHAUSER, C. Light signal transduction in higher plants. Annual Review Genetics, v. 38, p. 87-117, 2004.

CHOW, W. S.; MELIS, A.; ANDERSON, J. M. Adjustments of phosystem stoichiometry in chloroplasts improve the quantum efficiency of photosynthesis. Proceedings of the National Academy of Sciences, Washington, v. 87, p. 7502-7506, 1990.

CRITCHLEY, C. Molecular adaptation to irradiance: the dual functionality of photosystem II. In: SINGHAL, G. S.; RENGER, G.;SOPORY, S. K.; IRRGANG GOVINDJEE, K. (Eds.). Concepts in photobiology: photosynthesis and photomorphogenesis. New Delhi: Narosa Publishing House, 1999. p. 573-587.

CRUZ, J. L.; PELACANI, C. R.; CARVALHO, J. E.; SOUZA FILHO, L. F. S.; QUEIROZ, D. C. Níveis de nitrogênio e a taxa fotossintética do mamoeiro "golden". Ciência Rural, Santa Maria, v. 37, n. 1, p. 64-71, 2007.

DELIEU, T.; WALKER, D. A. Simultaneous measurement of oxygen evolution and chlorophyll by fluorescence from leaf pieces. Plant Physiology, Wageningen, v. 73, n. 3, p. 534-541, 1983.

DIGNART, S. L.; CASTRO, E. M. DE.; PASQUAL, M.; FERRONATO, A.; BRAGA, F. T.; PAIVA, R. Luz natural e concentrações de sacarose no cultivo in vitro de Cattleya walkeriana. Ciência e Agrotecnologia, v. 33, n. 3, p. 780787, maio/jun., 2009.

DISCHE, Z. General color reactions. In: WHISTLER, R. L.; WOLFRAM, M. L. (Eds.). Carhohydrate chemistry. New York: Academic, 1962. p. 477-512.

DOUSSEAU, S.; ALVARENGA, A. A. DE.; CASTRO, E. M. DE.; SOARES, R. P.; EMRICH, E. B.; MELO, L. A. DE. Anatomia foliar de Tabebuia serratifolia (Vahl) Nich. (Bignoniaceae) propagadas in vitro, in vivo e durante a aclimatização. Ciência e Agrotecnologia, v. 32, n. 6, p. 1694-1700, nov./dez., 2008.
EVANS, J. R.; SEEMAN, J. R. differences between wheat genotypes in specific activity of RuBP carboxylase and the relationship to photosynthesis. Plant Physiology, Wageningen, v. 74, p. 759-765, 1984.

HIGBY, W. K. A simplified method for determination of some the carotenoid distribution in natural and carotenefortified orange juice. Journal of Food Science, Amsterdam, v. 27, p. 42-49, 1962.

HUUB, L.; KERCKHOFFS, J.; KENDRICK, R. E. Photocontrol of anthocyanin biosynthesis in tomato. Journal of Plant Research, v. 110, n. 1, p. 141-149, 1997.

KERCKHOFFS, L. H.; GROOT, N. A. M. A. de; TUINEN, A. van; SCHREUDER, M. E. L.; NAGATANI, A.; KORNNEEF, M.; KENDRICK, R. E. Physiological characterization of exaggerated-photoresponse mutants of tomato. Journal of Plant Physiology, Wageningen, v. 150, p. 578-587, 1997.

KJELDAHL, J. Z. A new method for the determination of nitrogen in organic bodies. Analytical Chemistry, v. 22, p. $366,1883$.

KOORNEEF, M.; CONE, J. W.; DEKENS, R. G.; HERNEROBERS, E. G. o'; SPRUIT, C. J. P.; KENDRIK, R. E. Photomorphogenenic response of long-hypocotil mutants of tomato. Journal of Plant Physiology, Wageningen, v. 120, p. 153-165, 1985.

LIMA JUNIOR, E. C.; ALVARENGA, A. A.; CASTRO, E. M.; VIEIRA, C. V.; BARBOSA, J. P. R. A. D. Aspectos fisioanatômicos de plantas jovens de Cupania vernalis Camb. submetidas a diferentes níveis de sombreamento. Revista Árvore, Viçosa, v. 30, p. 33-41, 2006.

LIU, Y.; ROOF, S.; ZHIBIAO, Y.; BARRY, C.; TUINEN, A. van; VREBALOV, J.; BOWLER, C.; GIOVANNONI, J. Manipulation of light signal tranduction as a means of modifying fruit nutritional quality in tomato: PNAS plant biology. 2004. Disponível em: <hitp://www.pnas.org/misch rightperm.shtmil >. Acesso em: 13 nov. 2006.

LÓPEZ-JUEZ, E.; NAGATANI, A.; BUURMEIJER, W. F.; PETERS, J. L.; FERUYA, M.; KENDRICK, R. E.;

WESSELIUS, J. C. Response of light-growth wild-type and aurea mutant tomato plants to end-of-day far-red light. Journal Photochemistry and Photobiology, v. 4, p. 391-405, 1990. 
MARTÍ, E.; GISBERT, C.; BISHOP, G. J.; DIXON, M. S. Genetic and physiological characterization of tomato $\mathrm{cv}$. Micro-Tom. Journal of Experimental Botany, v. 57, n. 9, p. 2037-2047, 2006.

MEISSNER, R.; JACOBSON, Y.; MELAMED, S.; LEVYATUV, S.; SHALEY, G.; ASHRI, A.; ELKIND, Y.; LEVY, A. A new model system for tomato genetics. Plant Journal, v. 12, p. 1465-1472, 1997.

NAKAZONO, E. M.; COSTA, M. C.; FUTATSUGI, K.; PAULILO, M. T. S. Crescimento inicial de Euterpe edulis Mart. em diferentes regimes de luz. Revista Brasileira de Botânica, São Paulo, v. 24, p. 173-179, 2001.

PETERS, J. L.; SZELL, M.; KENRICK, R. E. The expression of light-regulated genes in the high-pigment1 mutant of tomato. Plant Physiology, Wageningen, v. 117, p. 797-807, 1998.

PRATT, L. H.; CORDONNIER-PRATT, M. M.; KELMENSON, P. M.; LAZAROVA, G. I.; KUBOTA, T.; ALBA, R. M. The phytochrome gene family in tomato (Solanum lycopersicon L.). Plant Cell and Environment, v. 20, p. 672-677, 1997.
SCHITTENHELM, S.; MENGE-HARTMANN, U.; OLDENBURG, E. Photosynthesis, carbohydrate metabolism, and yield of phytochrome-B-overexpressing potatoes under different light regimes. Crop Science, Madison, v. 44, p. 131-143, 2004.

SHARMA, R.; LÓPEZ-JUEZ, E.; NAGATANI, A.; FURUYA, M. Identification of photo-inactive phytochrome A in etiolated seedlings and photoactive phytochrome B in green leaves of aurea mutant of tomato. Plant Journal, v. 4, p. 1035-1042, 1993.

TERRY, M. J.; KENDRICK, R. E. Feedback inhibition of chlorophyll synthesis in the phytochrome chromophore-defidient aurea and yellow-green-2 mutants of tomato. Plant Physiology, Wageningen, v. 119, p. 143-152, 1999.

YEN, H. C.; SHELTON, B. A.; HOWARD, L. R.; LEE, S.; VREBALOV, J.; GIOVANNONI, J. J. The tomato high pigment (hp) locus to chromossome 2 and influences plastome copy number and fruit quality. Theoretical and Applied Genetics, v. 95, p. 1069-1079, 1997. 